\title{
The Utility of Adenotonsillectomy to Treat Snoring in Children: Acoustic Evaluation Using Smartphones
}

\author{
Sang Hoon Lee ${ }^{1}$, Soon Bok Kwon ${ }^{2}$, Ho Byung Lee ${ }^{1}$, Geun Hyung Park ${ }^{1}$, \\ Mi Jin Mun, Young Joong Kim¹, and Soo Kweon Koo ${ }^{1}$ \\ ${ }^{I}$ Department of Otorhinolaryngology-Head and Neck Surgery, Busan Saint Mary's Hospital, Busan; and \\ ${ }^{2}$ Department of Language and Information, College of Humanities, Pusan National University, Busan, Korea
}

\section{소아 코골이 환자의 치료에서 아테노이드편도 절제술의 유용성: 스마트폰을 이용한 음향학적 연구}

이상훈 ${ }^{1} \cdot$ 권순복 $^{2} \cdot$ 이호병 - 박근형 $^{1} \cdot$ 문미진 $^{1} \cdot$ 김영중 $^{1} \cdot$ 구수권 $^{1}$

부산성모병원 이비인후과, ${ }^{1}$ 부산대학교 인문대학 언어정보학과 ${ }^{2}$

Received December 23, 2017

Revised March 26, 2018

Accepted March 28, 2018

Address for correspondence

Soo Kweon Koo, MD, PhD

Department Otorhinolaryngology-

Head and Neck Surgery,

Busan Saint Mary's Hospital,

25-14 Yongho-ro 232beon-gil,

Nam-gu, Busan 48575, Korea

Tel $+82-51-933-7214$

Fax $+82-51-956-1956$

E-mail koosookweon@naver.com
Background and Objectives Adenotonsillectomy is a highly effective treatment for obstructive sleep apnea symptoms in children. In this study, to investigate the effects of adenotonsillectomy on snoring in children, we analyzed and compared snoring sounds recorded using a smartphone before and after adenotonsillectomy. We also determined whether it is possible to use acoustic analysis to monitor snoring in children.

Subjects and Method A total of 20 children diagnosed with snoring and had undergone adenotonsillectomy performed by the same surgeon were enrolled for the study. Snoring was recorded by patients' caregivers using smartphones before and after the surgery (mean of 8.5 days) and analyzed. Questionnaires were conducted by telephone survey at 3 months and 12 months after the surgery to determine snoring status.

Results Snoring completely ceased in $25 \%$ of patients and decreased in the remaining $75 \%$ during the immediate follow-up period (mean of 8.5 days; from $58.07 \pm 9.35 \mathrm{~dB}$ to $42.59 \pm 7.89$ $\mathrm{dB}, p<0.001$ ), and disappeared in all of the patients by 3 months after adenotonsillectomy. Snoring recurred only in one patient after 1 year. A frequency analysis offered no evident statistically significant changes during the immediate follow-up period, indicating that although snoring volume had decreased, no anatomical change had developed in the patient. Spectrography was useful in investigating the snoring patterns before and after adenotonsillectomy. Conclusion The results showed that acoustic analysis of snoring sounds obtained using a smartphone may be useful for monitoring snoring during follow-up after adenotonsillectomy in pediatric snoring patients. Korean J Otorhinolaryngol-Head Neck Surg 2018;61(9):465-71

Key Words Acoustics $\cdot$ Child $\cdot$ Sleep apnea, obstructive $\cdot$ Snoring $\cdot$ Tonsillectomy.

\section{Introduction}

The prevalence of obstructive sleep apnea (OSA) is about $1-3 \%$ in children aged $2-18$ years, and is the same in boys and girls. ${ }^{1)}$ The primary cause of pediatric snoring and OSA

This is an Open Access article distributed under the terms of the Creative Commons Attribution Non-Commercial License (https://creativecommons.org/licenses/by-nc/4.0) which permits unrestricted non-commercial use, distribution, and reproduction in any medium, provided the original work is properly cited. is enlargement of the tonsils and adenoids, which then obstruct the airway during the generalized loss of muscle tone that occurs during sleep. Removal of the tonsils and adenoids is therefore considered to be the first-line therapy. ${ }^{2-4)}$ Clinical symptoms attributable to adenotonsillar hypertrophy include behavioral impairments such as hyperactivity, aggression, anxiety, and depression; and neurocognitive impairments such as poor memory, inattention, or poor school 
performance. Adenotonsillectomy is highly effective when used to treat OSA symptoms, leading to normalization in $85 \%$ to $90 \%$ of cases. ${ }^{5,6)}$ Improvements are maintained for up to 2 years after surgery. ${ }^{7)}$

The outcomes of adenotonsillectomy to treat OSA can be objectively evaluated using data from pre- and post-operative polysomnography (PSG). However, overnight multi-channel PSG is time-consuming, labour-intensive in setting up, expensive, and difficult to perform especially in children. In fact, many patients cannot sleep well during PSG tests due to the discomfort of the enormous lead wire required for these. Therefore, there is a need for simplified recording and monitoring instruments that are capable of convenient and reliable screening of OSA at home. Nowadays, many researchers tend to use other measures such as physical parameters or questionnaires and numerous studies have developed portable technology. ${ }^{8)}$

Snoring is the major and most common manifestation of OSA and is caused by the vibration of soft tissues due to turbulent airflow through a narrow oropharynx in the upper airways. ${ }^{9,10)}$ Depending on the shape and physical dimensions of the upper airway, different snoring sounds with diverse acoustic properties are produced. These properties could be used to analyze snoring acoustically as a kind of signal resulting from the human upper airway structure. ${ }^{11)}$

In acoustic analysis, sound recording is important. To date, most studies have used expensive equipment in controlled laboratory settings, thus not reflecting sleep, snoring, or OSA patterns in real life. Recently, smartphones have been successfully used to record snoring sounds, facilitating self-monitoring of snoring, which is useful for general health care and telemedicine. ${ }^{11-13)}$

In this study, we analyzed and compared snoring sounds using intensity, formant frequency, and spectrography recorded with a smartphone, before and after adenotonsillectomy, and determined the effects of adenotonsillectomy on snoring in children. We also investigated the possibility of using smartphone-based acoustic analysis of child snoring as a follow-up tool after adenotonsillectomy to treat snoring.

\section{Subjects and Method}

\section{Patients}

Children presenting with snoring, mouth-breathing, and adenotonsillar hypertrophy, who underwent adenotonsillectomies by the same surgeon at our hospital from January 2016 to August 2016, were enrolled. Otorhinolaryngological examinations were conducted and cases with the following features were excluded: 1) younger than 3 or older than 18 years of age, 2) prior adenotonsillectomy, 3) craniofacial syndrome, neuromuscular disease, any genetic disorder, or developmental delay, 4) asthma, nasal septal deviation, chronic hypertrophic rhinitis, or allergic rhinitis, and 5) body mass index at the 95th percentile or higher. ${ }^{6}$ A total of 20 children were included in the study; 7 were boys (mean age of 5.3 years) and 13 were girls (mean age of 6.8 years). All of the children exhibited tonsil hypertrophy of more than Grade III, and the mean adenoid index was 0.8 (Table 1).

\section{Methods}

Before and after surgery (mean of 8.5 days), snoring in all of the patients was recorded by caregivers using smartphones, and analyzed. Telephone questionnaire surveys were conducted at 3 months and 12 months after surgery to explore snoring status. As a control group, three patients (mean age of 5.8 years) with Grade I tonsil hypertrophy were randomly selected and the intensity of snoring sound was measured. Recording of snoring sounds and acoustic analysis the smartphone operated on the Android system. A custom-made program on the smartphone acquired ambient sounds from the built-in microphone and analyzed it on a real-time basis. During sleep, caregivers recorded snoring sounds using smartphones. To eliminate possible differences among recording devices, we only used Samsung Galaxy smartphones (Samsung Electronics Ltd., Suwon, Korea). The smartphone was placed above the shoulder (within arm's reach) of each subject just before the child fell asleep. However, we did not impose any restriction regarding where the phone could be placed on the bed. $^{11,12)}$ We asked each caregiver to perform three recordings, and from these, selected the first snoring sounds made imme-

Table 1. Demographic data on children undergoing adenotonsillectomy to treat snoring

\begin{tabular}{lccc}
\hline & Male & Female & Total \\
\hline Number of patients & 7 & 13 & 20 \\
Age (years) & $5.3 \pm 1.9$ & $6.8 \pm 2.9$ & $6.3 \pm 2.6$ \\
Body mass index $\left(\mathrm{kg} / \mathrm{m}^{2}\right)$ & $16.1 \pm 3.4$ & $17.2 \pm 3.9$ & $16.8 \pm 3.6$ \\
Tonsil grade & & & \\
$\quad$ Right & $3.4 \pm 0.5$ & $3.3 \pm 0.5$ & $3.4 \pm 0.5$ \\
$\quad$ Left & $3.3 \pm 0.5$ & $3.2 \pm 0.4$ & $3.2 \pm 0.4$ \\
Adenoid index & $0.8 \pm 0.1$ & $0.8 \pm 0.2$ & $0.8 \pm 0.1$ \\
Snoring intensity (dB) & $62.9 \pm 6.2$ & $56.0 \pm 8.6$ & $58.4 \pm 8.4$ \\
\hline Values are mean \pm standard deviation & &
\end{tabular}

Values are mean \pm standard deviation 
diately after an OSA event developing during sleep. Each recording was a minimum of $10 \mathrm{sec}$ in length. ${ }^{11-13)}$ The acoustic characteristics of all three sounds were averaged and evaluated using Praat software (ver. 5.2.16; University of Amsterdam, Amsterdam, the Netherlands). The sampling rate was $44 \mathrm{kHz}$. We measured the sound intensity in decibel (dB), the formant frequencies, and the spectrographs of pre- and post-operative sleep.

\section{Questionnaire}

We asked whether snoring had disappeared or had recurred, and we explored caregiver subjective satisfaction using a Visual Analog Scale (VAS).

\section{Statistical analysis}

We evaluated differences in snoring sounds between preand post-operative sleep using the Wilcoxon signed-rank test. All of the statistical tests were performed with the aid of SAS software (ver. 9.4; SAS Inc., Cary, NC, USA). A $p$ value $<0.05$ was considered statistically significant. The study was approved by the Institutional Review Board of our hospital (IRB No. BSM-2017-07), and we obtained written parental informed consent.

\section{Results}

\section{Acoustic analysis}

The mean intensity of control group is $29.18 \mathrm{~dB}$. The mean intensity of pre-operative snoring (20 patients) was $58.07 \pm$ $9.35 \mathrm{~dB}, 880.48 \pm 273.01 \mathrm{~Hz}$ in the $\mathrm{F}_{1}$ formant and 1900.96 \pm $407.16 \mathrm{~Hz}$ in the $\mathrm{F}_{2}$ formant. During the immediate post-operative follow-up period (mean of 8.5 days), 5 patients exhibited complete loss of snoring and 15 patients had decreased but still audible snoring. The average snoring intensity in the latter 15 patients was $42.59 \pm 7.89 \mathrm{~dB}$, which was statistically significantly lower than the pre-operative snoring level (58.07士 $9.35 \mathrm{~dB}, p<0.001$ ), but we found no statistically significant change in formant frequency (Table 2).

\section{Spectrography}

Spectrography well revealed the snoring patterns before and after surgery. In children in whom snoring disappeared after adenotonsillectomy, spectrography only revealed background noise; the snoring waveform seen before operation disappeared (Fig. 1). In children who continued to snore after adenotonsillectomy, spectrography showed that the snoring waveform prior to adenotonsillectomy decreased (Fig. 2).

\section{Questionnaire responses}

Caregivers reported that the snoring intensity significantly decreased from $7.3 \pm 1.9$ to $1.0 \pm 1.1$ (using a VAS) 3 months after operation ( $p<0.001$; Table 3 , via telephone survey): all of the caregivers reported that snoring had ceased in all patients. Snoring recurred in only one patient after 1 year of operation; the grade rose from 0 ( 3 months after operation) to 7 (1 year after operation) on the VAS.

\section{Discussion}

The most accurate and comprehensive method used to diagnose OSA is multichannel full-night PSG, ${ }^{14)}$ but most studies have not performed PSG prior to adenotonsillectomy to treat OSA in pediatric patients ${ }^{15,16)}$ because of its cost and the fact that it is technically difficult and time-consuming, particularly in children. Therefore, many researchers tend to use other measures such as physical parameters or questionnaires but many screening tools based on physical parameters or questionnaires lack specificity. ${ }^{8)}$

Acoustic snoring analysis is a useful screening test, and many studies have used this approach since Ben-Israel performed the first analysis of snoring sounds. ${ }^{17)}$ Various parameters are used for acoustic analysis of snoring. Brietzke and Mair ${ }^{18)}$ showed the correlation between snoring intensity and the severity of OSA using acoustic analysis in pediatric patients. They showed a positive correlation between apneahypopnea index and the intensity of snoring. The mechanism how the severity of OSA influences the snoring intensity is not well known but it might be possible that negative pressure

Table 2. The intensities and formant frequencies of snoring during the pre-operative and immediate post-operative follow-up periods after adenotonsillectomy

\begin{tabular}{lccc}
\hline & Preoperative value & Postoperative value & $p$ value \\
\hline Snoring intensity $(\mathrm{dB})$ & $58.07 \pm 9.35$ & $42.59 \pm 7.89$ & $<0.001^{*}$ \\
$F_{1}(\mathrm{~Hz})$ & $880.48 \pm 273.01$ & $821.00 \pm 224.09$ & 0.804 \\
$\mathrm{~F}_{2}(\mathrm{~Hz})$ & $1900.96 \pm 407.16$ & $1874.72 \pm 305.69$ & 0.6 \\
\hline
\end{tabular}

Values are mean \pm standard deviation. $* p<0.05$. $F_{1}$ : first formant frequencies, $F_{2}$ : second formant frequencies 
generated during apnea might be higher in severe OSA patients such that the snoring intensity might be increased. ${ }^{19)}$ During our immediate post-operative follow-up, caregivers of snoring children felt subjectively that snoring and OSA symptoms were alleviated, and objectively, we found that snoring intensity was significantly reduced. Considering the results, snoring intensity may be associated with OSA severity. A spectrograph is a visual representation of the frequency spectrum of sound over time. We found that when snoring disappeared after adenotonsillectomy, the spectrograph only

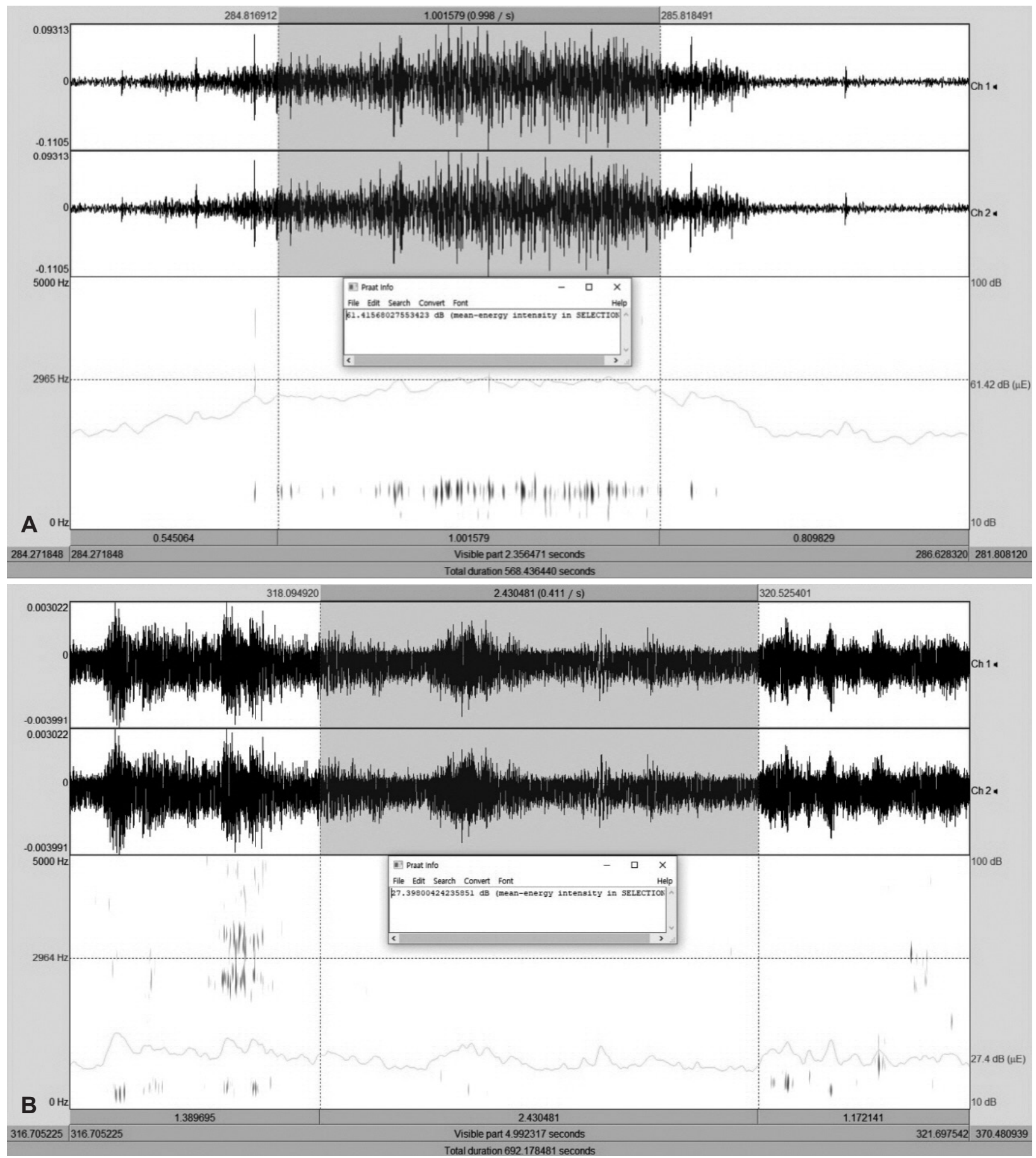

Fig. 1. A sample spectrograph of a child in whom snoring disappeared after adenotonsillectomy. The spectrograph shows that only background noise was observed; the snoring waveform evident before operation disappeared. A pre-operative spectrograph of a child in whom snoring disappeared after adenotonsillectomy (A). A post-operative spectrograph of a child in whom snoring disappeared after adenotonsillectomy $(B)$. 
exhibited background noise; the snoring waveform seen before operation disappeared. In children who continued to snore after adenotonsillectomy, spectrography showed that the snoring waveform evident before adenotonsillectomy decreased. Spectrography was useful reflecting snoring after surgery.
Similar to the vocal tract in speech production the upper airway acts as a variable acoustic filter in the generation of snoring sounds. ${ }^{11,20,21)}$ Depending on the shape and physical dimensions of the upper airway, different snoring sounds with diverse acoustic properties, or formant frequencies, are produced. In speech science, a formant is used to indicate the

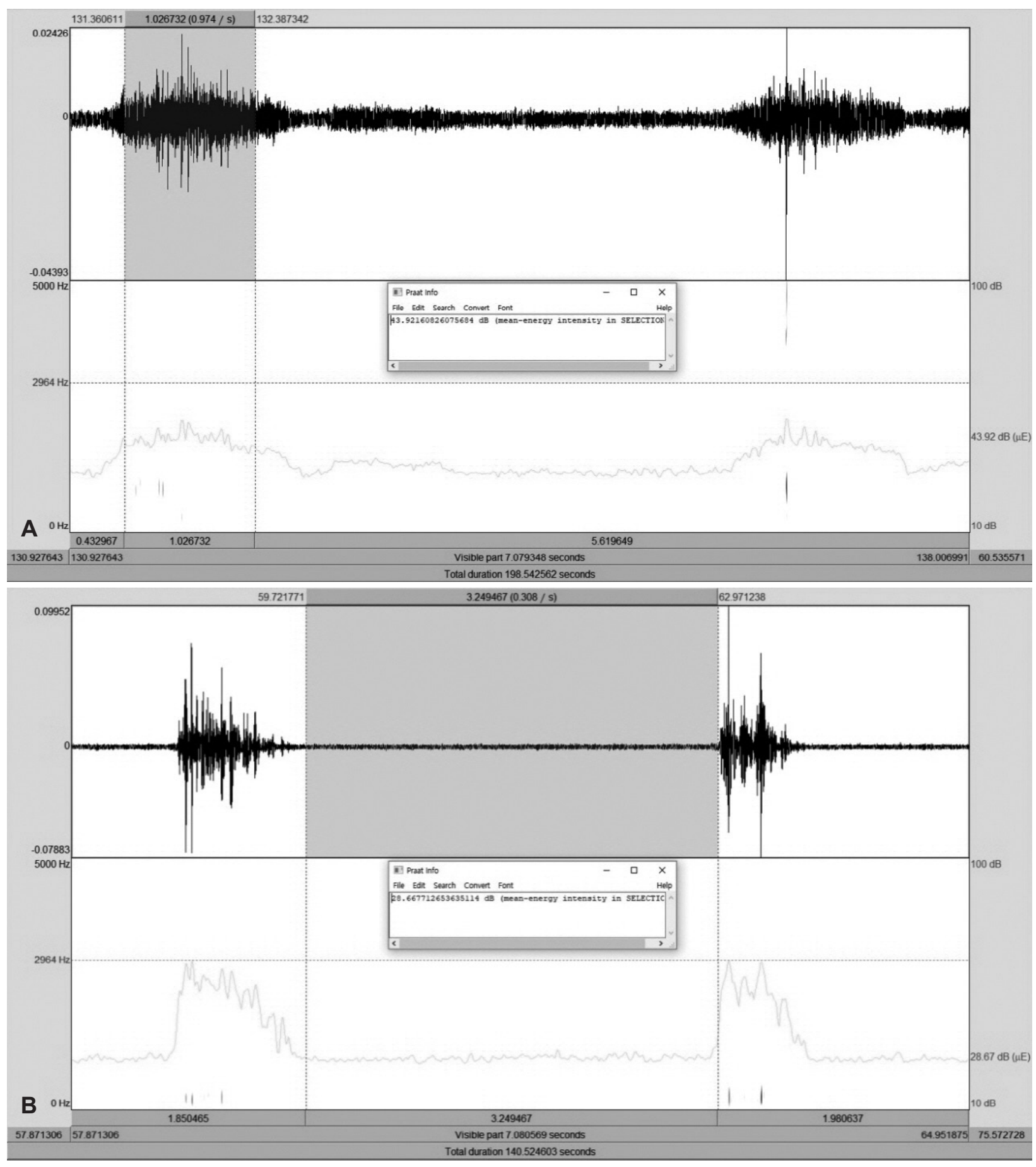

Fig. 2. A spectrograph of a child in whom snoring persisted after adenotonsillectomy. The spectrograph shows that the snoring waveform decreased after adenotonsillectomy. A pre-operative spectrograph of a child in whom snoring persisted after adenotonsillectomy (A). A post-operative spectrograph of a child in whom snoring persisted after adenotonsillectomy (B). 
Table 3. VAS of snoring during the pre- and 3-months post-operative follow-up periods after adenotonsillectomy

\begin{tabular}{cccc}
\hline & Preoperative value & Postoperative value & $p$ value \\
\hline VAS & $7.3 \pm 1.9$ & $1.0 \pm 1.1$ & $<0.001^{*}$
\end{tabular}

Values are mean \pm standard deviation. $* p<0.05$. VAS: Visual Analog Scale

acoustic resonance of the human vocal tract, and these properties could be used to analyze snoring as a kind of signal resulting from the human respiratory structure. Variation in the $F_{1}$ formant reflects airway changes in apneic snorers, whereas variation in the $F_{2}$ formant reflects changes in tongue morphology. ${ }^{11,20,21)}$ In contrast $F_{3}$ reflecting the shape of the lips, it was excluded because it is not meant in the research of the author.

In this study, our acoustic analysis of snoring sounds revealed no statistically significant difference in $F_{1}$ or $F_{2}$ snoring sound formant frequencies between the pre-operative and immediate post-operative snoring sounds (the latter evaluated at a mean of 8.5 days post-operatively). This means that snoring sounds decrease immediately post-operatively, but anatomical changes are somewhat delayed.

Recent research trends are taking place in living spaces non-PSG room and study with a smartphone has an advantage in this respect. Nakano, et al. ${ }^{22)}$ attempted to use a smartphone for monitoring snoring and OSA and proved to be considerably effective in detecting snoring and OSA events. Shin and $\mathrm{Cho}^{12)}$ set up the experimental recording system using smartphone, and they conclude that smart phones, could be a promising approach to record sleep patterns. So, we recorded snoring sound using smart and obtained a satisfactory result. Smartphone-based sleep measurement techniques have been developed to provide personalized sleep care. ${ }^{12)}$

The peak incidence of OSA is evident in those aged 4 to 6 years. ${ }^{23)}$ The mean age of our children was 6.3 years, and $70 \%$ were aged $<6$ years. The tonsils vary in size. Suen, et al. ${ }^{24)}$ reported that children with respiratory distress indices (RDIs) $\geq 5$ had significantly larger tonsils than those with RDIs $\leq 5$. Several studies have indicated that the prevalence of severe OSA increases as tonsil size increases. ${ }^{25)}$ However, the correlations between adenoid size and OSA have varied. ${ }^{26,27)}$ In our study, all of the cases were of Grade III or higher. The adenoid index ranged from 0.5 to 1.0 . Our case numbers were perhaps too small to allow us to reliably predicting snoring severity by tonsil size or the adenoid index; thus, more studies are needed.

Adenotonsillectomy is the primary treatment for pediatric
OSA patients. Li, et al. ${ }^{28)}$ reported significant improvements in respiratory parameters on the second night after adenotonsillectomy to treat OSA; sleep apnea symptoms also improved early in the follow-up period. We found that $25 \%$ of patients ceased snoring in the first week after surgery, and snoring fell in the remaining $75 \%$. Three months after operation, snoring had ceased in all patients, indicating the utility of adenotonsillectomy in this context. However, many recent studies have only reported partial resolution of OSA symptoms and parameters after adenotonsillectomy, and many patients required additional treatments for residual disease. ${ }^{29)}$ Indeed, in one study, the proportions of patients exhibiting permanent OSA after adenotonsillectomy were $16-27 \%$. Although adenotonsillectomy resolves OSA in the vast majority of children, persistent OSA remains challenging. ${ }^{23)}$ In this study, snoring recurred in only one of our patients 1 year after operation. This study, however, has some limitations. First, this study was performed using a home-based smartphone instead of gold standard PSG, therefore, this could be another study that may prove the validity of smartphone based snoring recording compared to standard PSG. It also there is no consideration of important factors such as sleep phase, sleeping posture and it is possible that the evaluation was not made under the same conditions before and after surgery. Second, the evaluation was not performed after the wound was fully healed and the number of subjects was relatively small compared with that in a previous study; more case studies with longer-term follow-up are needed.

In conclusion, immediately after adenotonsillectomy, snoring completely ceased in $25 \%$ of patients and decreased in the remaining $75 \%$ early in the follow-up period. Snoring ceased in all of the patients 3 months after adenotonsillectomy; only one recurrence was recorded after 1 year, consistent with both the acoustic analysis and the subjective views of the caregivers. Thus, acoustic analysis of snoring sounds obtained using a smartphone may be useful for monitoring snoring during follow-up after adenotonsillectomy in pediatric snoring patients.

\section{REFERENCES}

1) Redline S, Tishler PV, Schluchter M, Aylor J, Clark K, Graham G. Risk factors for sleep-disordered breathing in children. Associations with obesity, race, and respiratory problems. Am J Respir Crit Care Med 1999;159(5 Pt 1):1527-32.

2) Marcus CL, Moore RH, Rosen CL, Glordanl B, Garetz SL, Taylor $\mathrm{HG}$, et al. A randomized trial of adenotonsillectomy for childhood sleep apnea. N Engl J Med 2013;368(25):2366-76.

3) Marcus CL, Brooks LJ, Draper KA, Gozal D, Halbower AC, Jones 
$\mathrm{J}$, et al. Diagnosis and management of childhood obstructive sleep apnea syndrome. Pediatrics 2012;130(3):576-84.

4) Gysin C. Indications of pediatric tonsillectomy. ORL J Otorhinolaryngol Relat Spec 2013;75(3):193-202.

5) Brietzke SE, Gallagher D. The effectiveness of tonsillectomy and adenoidectomy in the treatment of pediatric obstructive sleep apnea/ hypoapnea syndrome: a meta-analysis. Otolaryngol Head Neck Surg 2006;134(6):979-84.

6) Mitchell RB. Adenotonsillectomy for obstructive sleep apnea in children: outcome evaluated by pre- and postoperative polysomnography. Laryngoscope 2007;117(10):1844-54.

7) Mitchell RB, Kelly J, Call E, Yao N. Long-term changes in quality of life after surgery for pediatric obstructive sleep apnea. Arch Otolaryngol Head Neck Surg 2004;130(4):409-12.

8) Kovacevic L, Wolfe-Christensen C, Lu H, Lulgjuraj M, Abdulhamid I, Thottam PJ, et al. Adenotonsillectomy improves quality of life in children with sleep-disordered breathing regardless of nocturnal enuresis outcome. J Pediatr Urol 2015;11(5):269.el-5.

9) Young T, Palta M, Dempsey J, Skatrud J, Weber S, Badr S. The occurrence of sleep-disordered breathing among middle-aged adults. N Engl J Med 1993;328(17):1230-5.

10) Ohayon MM, Guilleminault C, Priest RG, Caulet M. Snoring and breathing pauses during sleep: telephone interview survey of a United Kingdom population sample. BMJ 1997;314(7084):860-3.

11) Koo SK, Kwon SB, Kim YJ, Moon JI, Kim YJ, Jung SH. Acoustic analysis of snoring sounds recorded with a smartphone according to obstruction site in OSAS patients. Eur Arch Otorhinolaryngol 2017;274(3):1735-40.

12) Shin $H$, Cho J. Unconstrained snoring detection using a smartphone during ordinary sleep. Biomed Eng Online 2014;13:116.

13) Shin H, Choi W, Kim YG, Cho J. Preliminary study for the personal handheld device based snoring detection in ordinary sleep situation. Conf Proc IEEE Eng Med Biol Soc 2014;2014:3687-90.

14) Marcus CL, Annett RD, Brooks LJ, Brouillette RT, Carroll JL, Givan D, et al. Cardiorespiratory sleep studies in children: establishment of normative data and polysomnographic predictors of morbidity. Am J Respir Crit Care Med 1999;160(4):1381-7.

15) Weatherly RA, Mai EF, Ruzicka DL, Chervin RD. Identification and evaluation of obstructive sleep apnea prior to adenotonsillectomy in children: a survey of practice patterns. Sleep Med 2003;4(4):297-307.

16) Mitchell RB, Pereira KD, Friedman NR. Sleep-disordered breathing in children: a survey of practice patterns. Laryngoscope 2006;116(6): 956-8.
17) Ben-Israel N, Tarasiuk A, Zigel Y. Obstructive apnea hypopnea index estimation by analysis of nocturnal snoring signals in adults. Sleep 2012;35(9):1299-305.

18) Brietzke SE, Mair EA. Acoustical analysis of pediatric snoring: what can we learn? Otolaryngol Head Neck Surg 2007;136(4):644-8.

19) Kim JW, Lee CH, Rhee CS, Mo JH. Relationship between snoring intensity and severity of obstructive sleep apnea. Clin Exp Otorhinolaryngol 2015;8(4):376-80.

20) Koo SK, Kwon SB, Chon KM, Kim YJ, Kim YJ. The role of the maxillary sinus on the voice. Eur Arch Otorhinolaryngol 2015;272 (9):2347-50.

21) Ng AK, Koh TS, Baey E, Lee TH, Abeyratne UR, Puvanenfran K. Could formant frequencies of snore signals be an alternative means for the diagnosis of obstructive sleep apnea? Sleep Med 2007;9(8): 894-8.

22) Nakano H, Hirayama K, Sadamitsu Y, Toshimitsu A, Fujita H, Shin $\mathrm{S}$, et al. Monitoring sound to quantify snoring and sleep apnea severity using a smartphone: proof of concept. J Clin Sleep Med 2014;10 (1):73-8.

23) Borovich A, Sivan Y, Greenfeld M, Tauman R. The history of primary snoring in children: the effect of adenotonsillectomy. Sleep Med 2016;17:13-7.

24) Suen JS, Arnold JE, Brooks LJ. Adenotonsillectomy for treatment of obstructive sleep apnea in children. Arch Otolaryngol Head Neck Surg 1995;121(5):525-30.

25) Nolan J, Brietzke SE. Systematic review of pediatric tonsil size and polysomnogram-measured obstructive sleep apnea severity. Otolaryngol Head Neck Surg 2011;144(6):844-50.

26) Hwang SH, Guilleminault C, Park CS, Kim TW, Hong SC. Usefulness of adenotonsillar size for prediction of severity of obstructive sleep apnea and flow limitation. Otolaryngol Head Neck Surg 2013;149(2): 326-34.

27) Kang KT, Chou CH, Weng WC, Lee PL, Hsu WC. Associations between adenotonsillar hypertrophy, age, and obesity in children with obstructive sleep apnea. PLoS One 2013;8(10):e78666.

28) Li AM, Wing YK, Cheung A, Chan D, Ho C, Hui S, et al. Is a 2-night polysomnographic study necessary in childhood sleep-related disordered breathing? Chest 2004;126(5):1467-72.

29) Bhattacharjee R, Kheirandish-Gozal L, Spruyt K, Mitchell RB, Promchiarak J, Simakajornboon N, et al. Adenotonsillectomy outcomes in children with obstructive sleep apnea in children: a multicenter retrospective study. Am J Respir Crit Care Med 2010; 182(5):676-83. 